\title{
A PESQUISA-AÇÃO E AS SUAS CONTRIBUIÇÕES PARA A CIÊNCIA METODOLÓGICA: ASPECTOS GERAIS
}

\section{ARTIGO ORIGINAL}

DENDASCK, Carla Viana ${ }^{1}$

DENDASCK, Carla Viana. A pesquisa-ação e as suas contribuições para a ciência metodológica: aspectos gerais. Revista Científica Multidisciplinar Núcleo do Conhecimento. Ano. 06, Ed. 11, Vol. 11, pp. 118-135. Novembro de 2021. ISSN: 24480959, Link de acesso: https://www.nucleodoconhecimento.com.br/educacao/aciencia-metodologica, DOI: 10..32749/nucleodoconhecimento.com.br/educacao/aciencia-metodologica

\section{RESUMO}

Em virtude do aumento da popularidade e possibilidade de uso da pesquisa-ação, o instrumento passou a ser utilizado de maneira significativa, porém, com conceito ainda não consolidado, o termo tem sido aplicado de maneira abstrata, sem interpretações profundas e detalhadas quanto ao uso em diversos contextos. Pretende-se esclarecer ao longo deste artigo o significado do termo, e, como este tipo de instrumento pode ser aplicado da melhor forma, atuando dentro da esfera do rigor científicometodológico. Tem-se como problema de pesquisa: quais as possibilidades de uso da pesquisa-ação, suas etapas e cuidados fundamentais? A relevância da ferramenta reside no fato de que permite a realização de uma pesquisa de maneira sistematizada, contínua e empiricamente embasada. Assim, discutir-se-á sobre o papel da teoria na pesquisa-ação e apontar-se-á as características inerentes às suas fases fundamentais. Algumas questões comuns relativas ao método, como, por exemplo, a participação do pesquisador, a função social da reflexão, a necessidade de gerir o conhecimento adquirido e a ética em pesquisa dever-se-ão ser consideradas.

\footnotetext{
${ }^{1}$ Teóloga, Doutora em Psicanálise Clínica. Atua há 15 anos com Metodologia Científica ( Método de Pesquisa) na Orientação de Produção Científica de Mestrandos e Doutorandos. Especialista em Pesquisas de Mercado e Pesquisas voltadas à área da Saúde. Doutoranda em Comunicação e Semiótica (PUC SP).

$\mathrm{RC}: 101855$

Link de acesso: https://www.nucleodoconhecimento.com.br/educacao/a-cienciametodologica
} 
Apresenta-se, por fim, alguns "modelos" de pesquisa-ação que podem contribuir com os pesquisadores na escolha e organização metodológicas.

Palavras-chave: Pesquisa-ação, Métodos de Pesquisa, Ferramentas de Pesquisa.

\section{INTRODUÇÃO}

A pesquisa-ação é um tipo de pesquisa que demanda, do participante, uma postura engajada (TRIPP, 2005). É uma estratégia, de certa forma, oposta à pesquisa tradicional, sendo esta considerada como "independente", "não-reativa" e "objetiva" (ENGEL, 2000). Assim sendo, como o próprio termo indica, a pesquisa-ação visa unir a pesquisa à ação, ou seja, à prática. Com isso, entende-se o conhecimento e a compreensão como parte da prática, sendo, então, uma forma de se empregar a pesquisa em situações em que o pesquisador também possui uma inclinação prática e deseja melhorar a compreensão de uma teoria (KOERICH et al, 2009). As argumentações contrárias a pesquisa-ação se dão especialmente pelo fato do pesquisador envolver-se no campo estudado, o que iria de encontro aos pressupostos da ética na pesquisa científica que recomenda a isenção do pesquisador como parte do processo de qualidade científica, aludindo que esta isenção seria responsável por trazer clareza nas argumentações do pesquisador que estaria ausente do tendencialismo na produção dos resultados (TRIPP, 2005; KOERICH et al, 2009).

Esse tipo de pesquisa surgiu da necessidade de superar uma lacuna existente entre os eixos da teoria e da prática. Uma de suas características predominantes é que se trata de uma pesquisa a partir da qual tenta-se intervir na prática de maneira inovadora durante o desenvolvimento da pesquisa. Não é apenas uma recomendação que aparece na etapa final (ENGEL, 2000). Essa vertente tem sido explorada especialmente pelos programas que visam promover o pragmatismo como produto final, como por exemplo, nos Programas de Pós-Graduação de Engenharias, Negócios, ou ainda, nos Programas de Mestrado e Doutorado Profissionais.

Um dos primeiros a introduzir a pesquisa-ação no contexto acadêmico foi o psicólogo alemão Kurt Lewin. Todavia, já na década de 1960, a Sociologia, rapidamente, RC: 101855

Link de acesso: https://www.nucleodoconhecimento.com.br/educacao/a-cienciametodologica 
apropriou-se do conceito (TRIPP, 2005). Partia-se do pressuposto de que o pesquisador deveria abandonar essa postura mais passiva, isolada, assumindo, portanto, as consequências provocadas pelos resultados de suas pesquisas, sendo que tais resultados deveriam ser colocados em prática, atendendo assim, uma demanda que buscava mais contribuição do contexto acadêmico para o mundo prático (FRANCO, 2005).

Esta busca surge então na mudança de postura teórica, para uma postura prática que possa interferir no curso dos acontecimentos. Nesse contexto, além da sua aplicabilidade no âmbito das ciências sociais e da própria psicologia, hoje, as suas possibilidades de uso são amplas, o que justifica a relevância deste estudo. Uma de suas novas possibilidades é o emprego na área da educação, desenvolveu-se como resposta às demandas tangentes à implementação da teoria educacional na prática docente, isto é, nas salas de aula (ENGEL, 2000). Hoje, um dos resultados da pesquisa-ação no universo da educação, pode ser constado através dos inúmeros materiais que trabalham com metodologias ativas, impulsionando inclusive, para que o conceito de metodologia ativa passasse a ser incorporado por alguns pesquisadores como disciplina e metodologia independente.

Como já aludido anteriormente, a teoria e prática não eram percebidas como partes inerentes à vida profissional. Diante de tais mudanças, a pesquisa-ação começou a ser implementada nos mais diversos contextos (TRIPP, 2005). O intuito é o de auxiliar os pesquisadores e profissionais a resolverem os problemas que afetam a sua prática laboral diária, envolvendo-se muito mais com a pesquisa (MIRANDA; RESENDE, 2006). Com isso, passou-se, no campo da educação, a avaliar, de maneira empírica, os valores, percepções e crenças no exercício do ensino-aprendizagem (ENGEL, 2000). Entende-se que este tipo de pesquisa tem sido visto com bons olhos pelos mais diversos acadêmicos. É uma pesquisa atrativa pelo fato de conduzir o pesquisador a um resultado específico e imediato em relação a um certo problema de pesquisa (GRITTEM; MEIER; ZAGONEL, 2008). 
Menciona-se que a pesquisa-ação tem se revelado como um instrumento eficiente ao desenvolvimento profissional dos mais diversos pesquisadores. Aponta-se que esse processo ocorre de "dentro para fora", uma vez que parte das preocupações e interesses das pessoas envolvidas na prática da pesquisa (TRIPP, 2005). Os sujeitos são envolvidos com questões que fomentam o seu próprio desenvolvimento profissional e, também, pessoal. A abordagem contrária à pesquisa-ação é justamente a pesquisa tradicional, pois a pesquisa ocorre de "fora para dentro" (ENGEL, 2000). Nesse processo, canônico, portanto, o pesquisador alimenta o seu estudo com as percepções trazidas de uma experiência externa, sendo essa experiência coletada por meio de certas ferramentas de pesquisa (como questionários e entrevistas) (FRANCO, 2005). Todavia, não se tem objetivo discutir sobre uma abordagem ideal, pois são propostas únicas e diferentes entre si. São dois modos de encarar a natureza da pesquisa científica.

Parte-se do pressuposto de que as verdades científicas existem no mundo externo à pesquisa, cabendo, ao cientista, descobrir tais verdades, incluindo a capacidade de intervenção para testar tais verdades. Todavia, na pesquisa científica, infere-se que há modos de se encarar a natureza de uma pesquisa, de forma que não há verdades científicas absolutas, pois, todo conhecimento é provisório e muda de acordo com o contexto histórico em que se vive (MIRANDA; RESENDE, 2006).

Os fenômenos são observados, bem como interpretados de acordo com tais particularidades históricas e culturais. Menciona-se, também, que os próprios padrões de pesquisa estão sujeitos à mudança, pois a ciência evolui a cada dia. Não há uma metodologia científica universal e histórica, mas modos distintos de se olhar para o mundo sob o viés científico (GRITTEM; MEIER; ZAGONEL, 2008). A pesquisa-ação, nesse sentido, aproxima-se de um olhar mais prático quanto aos fenômenos e situações cotidianas. Assim, os conhecimentos científicos são tidos como provisórios e dependentes de um contexto.

Considerando a esfera da educação, entende-se que os professores, ao invés de serem meros consumidores de uma pesquisa realizada por outros, devem transformar 
a sua própria prática docente por meio dos resultados desse estudo (ENGEL, 2000). Destarte, concebe-se a pesquisa-ação como o instrumento ideal à execução de uma pesquisa que deseja unir a teoria à prática. Nesse sentido, o objetivo geral desta pesquisa é, por meio de um estudo exploratório e descritivo, refletir sobre as possibilidades de aplicação da pesquisa-ação em qualquer ambiente de interação social. Tem-se como problema de pesquisa: quais as possibilidades de uso da pesquisa-ação e as suas etapas e cuidados fundamentais? A partir do problema, visase verificar como um ambiente no qual a interação social ocorre e que detém um problema real e urgente pode ser beneficiado com esse tipo de estudo, ambiente este que envolve pessoas, tarefas e procedimentos que necessitam de auxílio.

\section{A PESQUISA-AÇÃO E A SUA INFLUÊNCIA NA PRÁTICA SOCIAL}

A literatura descreve a trajetória da pesquisa-ação desde os anos de 1940. A partir de uma visão ampla, esta pode ser situada em dois períodos significativos: o primeiro está ligado a uma corrente norte-americana, marcada pela emergência do termo cunhado por Kurt Lewis no período que antecedeu à Segunda Guerra Mundial (MIRANDA; RESENDE, 2006). Esta fase perdura até a década de 1960. O segundo momento, por sua vez, está marcado por uma corrente europeia, corrente esta que contempla o período da década de 1960 até os dias atuais (BARBIER, 2002; MORIN, 2004). As duas vertentes apresentam um panorama geral sobre esse tipo de pesquisa, concentrando-se na abordagem qualitativa empregada pelas pesquisas em ciências sociais. Os conceitos, as justificativas e explicitações metodológicas construídas por meio de vinculações teórico-metodológicos demarcavam as pesquisas realizadas até então (BARBIER, 2002; MORIN, 2004).

Surge, daí, a noção de intervenção, sendo que esta pode variar de uma posição mais ligada aos estudos experimentais até os projetos de ação social, cujo intuito é a resolução dos mais diversos problemas sociais (THIOLLENT, 1984). Em virtude dos diversos conceitos e autores que passaram a discutir sobre a pesquisa-ação, diversas leituras e interpretações tornaram-se constantes, pendendo-se ora para uma perspectiva mais explicativa (experimental), ora para uma mais compreensiva

RC: 101855

Link de acesso: https://www.nucleodoconhecimento.com.br/educacao/a-ciencia-

metodologica 
(fenomenológica ou dialética) (TRIPP, 2005). A pesquisa-ação surge como uma crítica, inicialmente, ao positivismo, mesmo que se entenda que nem todas se afastaram de tal compreensão. Em princípio, situam-se, também, como abordagens de caráter compreensivo, pois reconhecem a realidade social como algo que não existe ou pode ser reconhecido como independente e autônomo (FRANCO, 2005). Trata-se, então, de uma realidade subjetiva e, como tal, é construída e sustentada por meio de atos individuais.

São esses atos individuais que atribuem sentidos e significados a essa realidade em processo de construção (CARR; KEMMIS, 1988). Dentre outros aspectos, pode-se mencionar, também, que há um paralelo entre essas novas releituras da pesquisaação. As abordagens francesa e canadense, propostas, respectivamente, por René Barbier (2002) e André Morin (2004), se conectam. Ao tomar como referência esses autores, bem como algumas de suas obras, não se pretende generalizar o seu pensamento e forma de produção desse tipo de estudo, mas sim elencar alguns de seus elementos gerais, pois esses permitem entender, de maneira profunda, os desdobramentos da pesquisa-ação nos mais diversos contextos (TRIPP, 2005). O campo da educação, como mencionado, é uma das possibilidades de espaços nos quais a pesquisa-ação pode agir de maneira significativa. Além disso, atribui-se, à pesquisa-ação, um sentido: esta é qualificada como uma revolução epistemológica (BARBIER, 2002).

É designada dessa forma, pois, até então, a proposta não havia sido explorada de modo significativo no âmbito das ciências humanas. Assim sendo, entendia-se que a pesquisa-ação, era uma espécie de "arte de rigor clínico" (BARBIER, 2002). Assim sendo, pode ser desenvolvida junto a uma coletividade. O objetivo, então, é o de analisar uma parcela dessa sociedade de uma maneira menos distante, menos objetiva, como ocorre nas pesquisas tradicionais, em que se defende a neutralidade e o distanciamento do pesquisador (TRIPP, 2005). Todavia, a fim de que esse tipo de estudo torne-se viável, implica uma mudança de postura do sujeito, seja ele um indivíduo ou um grupo social, no que toca à sua realidade (KOERICH et al, 2009). Precisa-se, então, fornecer percepções e opiniões reais sobre um dado fenômeno RC: 101855

Link de acesso: https://www.nucleodoconhecimento.com.br/educacao/a-cienciametodologica 
experienciado no dia a dia. O pesquisador, portanto, capta esse fenômeno e o registra, unindo essas percepções, valores e crenças do sujeito/grupo analisado com as suas concepções teóricas.

O exercício da pesquisa-ação implica que o pesquisador adote uma visão sistêmica aberta para registrar os fenômenos observados. Assim sendo, no ato do registro, deve combinar certos processos, como a organização, a informação, as percepções, os valores, as crenças, com as fontes das quais parte para construir o seu estudo de acordo com o rigor científico exigido (MIRANDA; RESENDE, 2006). A proximidade do pesquisador do fenômeno que está sendo investigado é um dos aspectos que distancia a pesquisa-ação daquelas mais canônicas, teóricas, apenas. Isso acontece em virtude dos próprios pressupostos que alicerçam esta ferramenta desde o momento de sua criação (ENGEL, 2000). Os autores pioneiros na área, em seus estudos, tecem críticas quanto à ação do positivismo no domínio das ciências sociais, visto que esta tendência introduziu limites à atividade da pesquisa, sendo que esta passou a se amparar em alguns pilares, como a objetividade, racionalidade e verdade (KOERICH et al, 2009).

A pesquisa-ação é vinculada à ideia de mudança constante e, dessa forma, parte-se do pressuposto de que os atores que constituem a realidade também estão em constante processo de transformação (TRIPP, 2005). Diante dessa mentalidade, surgiu a necessidade de pensar o conceito de pesquisa junto à ação, ou seja, à prática, e, com isso, passou-se a refletir sobre as estratégias de resolução de problemas sociais a partir de uma outra abordagem (FRANCO, 2005). Nesse contexto, os estudos que optam por esta abordagem de pesquisa conciliam os campos da prática, da ação social, com o teórico, epistemológico. A prática, ou seja, a ação, diz respeito a tudo que é constituído e mantido em um dado contexto e, com isso, abrange-se, também, a ação e a experiência diária de um sujeito (GRITTEM; MEIER; ZAGONEL, 2008). A pesquisa-ação é mais do que uma abordagem metodológica. Trata-se de um posicionamento diante de questões epistemológicas essenciais, como a relação entre sujeito e objeto, teoria e prática. 


\section{CARACTERÍSTICAS DE UMA PESQUISA-AÇÃO}

A pesquisa-ação abarca um processo empírico, sendo que este admite a identificação do problema dentro de um contexto social e/ou institucional, o levantamento dos dados tocantes ao problema em questão e a análise dos significados e sentidos atribuídos aos dados atinentes aos participantes (TRIPP, 2005). Além da identificação da necessidade de uma mudança e o levantamento acerca das possíveis soluções necessárias, a pesquisa-ação também intervém no ambiente prático, pois provoca e impulsiona a transformação (ENGEL, 2000). Trata-se de uma ferramenta metodológica capaz de aliar a teoria à prática por meio de uma ação que objetiva a transformação de um dado contexto, ou seja, de uma certa realidade (MIRANDA; RESENDE, 2006). A pesquisa-ação, então, permite associar, ao processo de investigação, a possibilidade de aprendizagem, visto que demanda o envolvimento criativo e consciente, tanto do pesquisador como dos demais integrantes da pesquisa (ROLIM et al, 2004).

Surge, nesse contexto, a importância da pesquisa-ação como instrumento de caráter multidisciplinar, visto que, ao mesmo tempo, atua em diversos campos, como no setor da saúde, no campo da educação, nos ambientes marcados pela inovação e mudança, dentre outros (TRIPP, 2005). Pode-se contemplar diferentes grupos, como profissionais, gestores, alunos e a população em geral, tanto nas comunidades quanto nas instituições (ROLIM et al, 2004). Há algumas características que demarcam a pesquisa-ação, como, por exemplo, a conceituação dos problemas que serão trabalhados, o planejamento, a execução e a avaliação de ações para resolvê-los. Há, na sequência, a repetição desse ciclo de atividades (ANDRÉ, 2000). Além de sua notória contribuição social, o trabalho de Lewin sobre a pesquisa-ação foi considerado como inovador, pois promove, ao mesmo tempo, o caráter participativo e democrático, uma vez que a pesquisa se desenvolve a partir da participação dos sujeitos estudados (TRIPP, 2005).

A pesquisa ação adotará os seguintes processos em sua construção: 
Tabela 1- Etapas da Pesquisa-Ação

\section{ETAPAS DA PESQUISA AÇÃO}

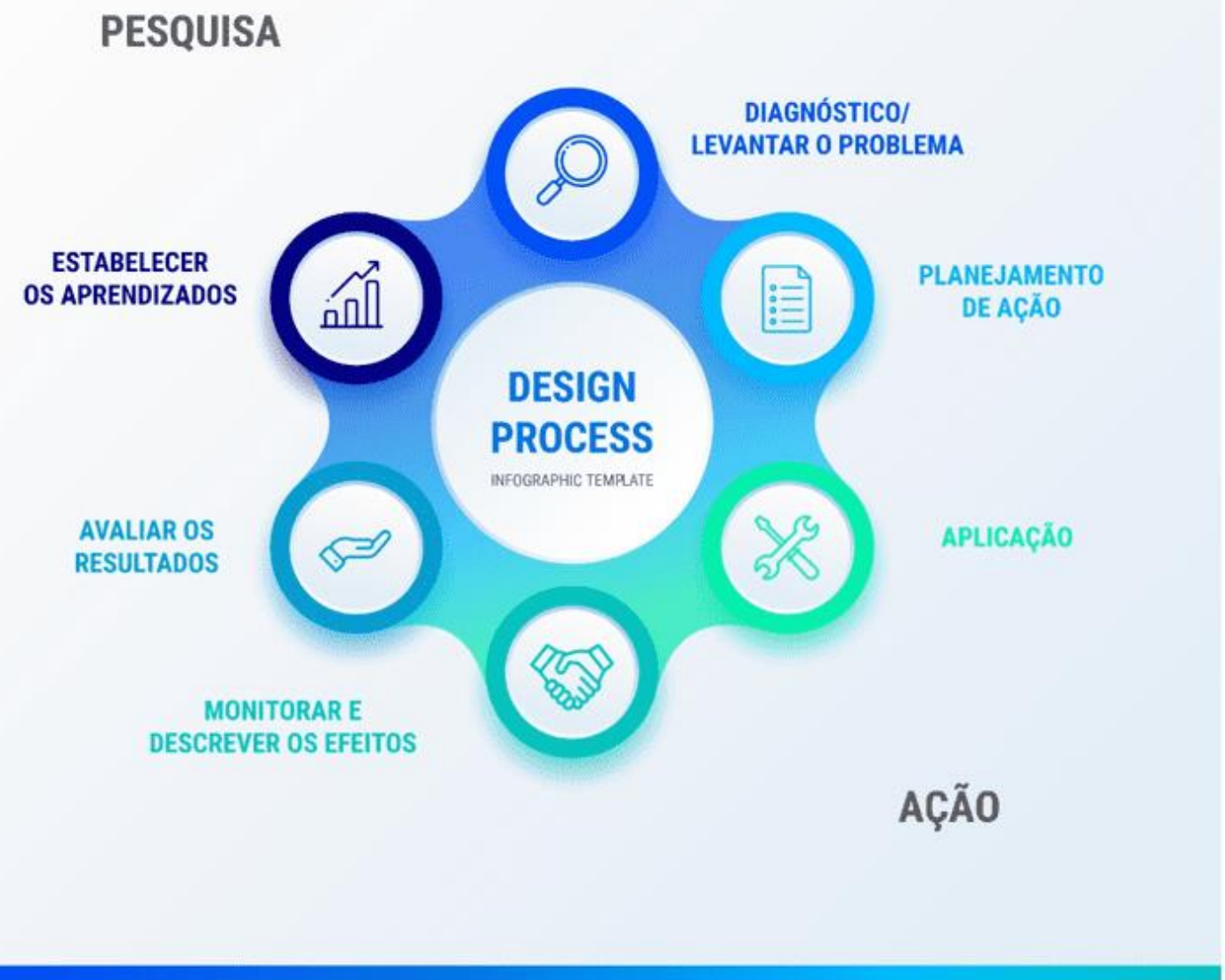

Fonte: Autora.

Assim sendo, tem-se um estudo orientado para a resolução de problemas que afetam um dado ambiente, concentrando-se, portanto, nas especificidades desse contexto, onde esses problemas se manifestam (PEREIRA, 2001; LEWIN, 1946). Uma outra característica desse tipo de pesquisa é a preocupação com a validade científica dos resultados obtidos junto aos colaboradores. Nesse processo, considera-se os diagnósticos, pois eles apontam a situação antes e depois do emprego de certas ações, assim como permitem o registro detalhado de todos os acontecimentos RC: 101855

Link de acesso: https://www.nucleodoconhecimento.com.br/educacao/a-cienciametodologica 
(LEWIN, 1946). A compreensão do instrumento de pesquisa aqui discutido está relacionada a dois conceitos fundamentais, sendo eles 0 ato de investigação e 0 ato substantivo. $O$ ato de investigação trata-se de uma ação capaz de impulsionar e fomentar uma indagação (TRIPP, 2005). O ato substantivo, por sua vez, trata-se de uma ação capaz de promover uma mudança almejada em um dado contexto observado e estudado.

Trata-se, portanto, de um processo que une a investigação à ação (KOERICH et al, 2009). Nesse sentido, na investigação-ação, os atos, necessariamente, são caracterizados como do tipo substantivo. Assim sendo, em virtude dessa qualificação, o ato de investigar pressupõe uma obrigação, que é a necessidade de beneficiar as pessoas que não pertencem à comunidade científica, mas podem ser beneficiadas com os resultados de um estudo científico (LEWIN, 1946). Assim sendo, a ciência, a partir de seus pesquisadores, assume uma nova missão: fazer com que o conhecimento produzido nas universidades, sejam elas nacionais ou estrangeiras, chegue até a sociedade laica, a fim de que os sujeitos que compõem os mais diversos grupos sociais sejam emancipados (FRANCO, 2005). A pesquisa-ação idealizada por Lewin tem sido empregada a partir de maneiras distintas e com diversas finalidades, dando origem a um amplo mosaico de abordagens teórico-metodológicas.

Há pelo menos três conceituações diferentes aplicadas à pesquisa-ação no Brasil. Elas são classificadas a partir de alguns critérios. O primeiro tipo é a pesquisa-ação colaborativa (a transformação é solicitada pelo grupo de referência à equipe de pesquisadores) (KOERICH et al, 2009). A função do pesquisador, nesse processo, é a de fazer parte de uma mudança, tornado esta científica. Esta é desencadeada pelos sujeitos que fazem parte do grupo (TRIPP, 2005). Há, também, a pesquisa-ação crítica. Percebe-se a necessidade de transformação a partir dos estudos iniciais do pesquisador junto ao grupo (FRANCO, 2005). Quando a mudança decorre de um processo que valoriza a construção cognitiva da experiência, sustentada pela reflexão crítica coletiva, com intuito de emancipar os sujeitos e eliminar condições que o coletivo considera como opressivas, a pesquisa assume um caráter essencialmente crítico (ENGEL, 2000). Há, também, a pesquisa-ação estratégica.

RC: 101855

Link de acesso: https://www.nucleodoconhecimento.com.br/educacao/a-cienciametodologica 
Se nas outras abordagens a transformação é previamente planejada, sem a atuação ativa dos sujeitos, o mesmo não ocorre aqui. Se há apenas um pesquisador responsável por avaliar e acompanhar os resultados da aplicação do estudo, a pesquisa ação-crítica perde o seu viés crítico (FRANCO, 2005). Para que a pesquisaação crítica seja caracterizada dessa forma, requer-se um mergulho na práxis do grupo social que está sendo analisado, cujo objetivo é o de extrair as perspectivas latentes que sustentam as práticas, ou seja, as mudanças são negociadas e administradas no coletivo (KOERICH et al, 2009). A pesquisa-ação colaborativa, nesse âmbito, assume, também, um caráter crítico (THIOLLENT, 1984). A criticidade que emana deste tipo de estudo demanda um processo de reflexão coletivo sobre as estratégias operacionais a serem adotadas. Considera-se nesse processo a voz do sujeito, assim como as suas perspectivas. O interesse não apenas no registro e em uma interpretação posterior.

É uma parte indissociável desta metodologia investigativa, de modo que esta não pode ser estabelecida por meio de etapas lineares voltadas ao método propriamente tidos, mas se organiza a partir de situações e fatos que emergem no processo e se tornam essenciais (ENGEL, 2000). Surge, então, a ênfase no caráter formativo desta modalidade de pesquisa, de modo que o sujeito deve tomar consciência acerca das transformações que afetam tanto o pesquisador quanto o grupo e o processo (TRIPP, 2005). Em virtude desse objetivo, a pesquisa-ação assume um caráter emancipatório, de modo que os sujeitos atuantes da pesquisa podem se libertar de mitos e preconceitos que impedem a chegada às mudanças desejadas (BARBIER, 2002). Este tipo de pesquisa, ao longo dos anos, como mencionado, sofreu influência de correntes positivistas, visto que incorporou-se, na vida cotidiana, a dialética da realidade social, assim como os pontos que alicerçam e sustentam a disseminação de uma racionalidade crítica linear.

Diante desse cenário, o estatuto epistemológico que ampara a pesquisa-ação passou a se preocupar com os processos por detrás da transformação social, estando ela comprometida com os aspectos éticos e políticos relacionados à emancipação dos sujeitos, concentrando-se, também, nas condições que amparam o processo RC: 101855

Link de acesso: https://www.nucleodoconhecimento.com.br/educacao/a-cienciametodologica 
emancipatório (MIRANDA; RESENDE, 2006). A pesquisa-ação passou a admitir algumas abordagens interpretativas de análise e recebeu uma estrutura capaz de fomentar a participação crítica dos envolvidos, o que fez com que o processo de pesquisa admitisse as reconstruções, bem como as ressignificações de significados e caminhos em toda a execução das etapas (TRIPP, 2005). Assumiu uma forma caracterizada como pedagógica e política (THIOLLENT, 1984). No contexto da pesquisa qualitativa, há três dimensões que devem ser consideradas pela pesquisaação. A primeira delas é a ontológica. Ela diz respeito à natureza do objeto a ser conhecido e investigado pelo pesquisador.

A segunda dimensão é a epistemológica e diz respeito ao sujeito que se busca conhecer. A terceira dimensão, por fim, é a metodológica, cujo objetivo é o conhecer os processos a partir dos quais o conhecimento foi construído pelo pesquisador envolvido com um certo grupo (FRANCO, 2005). No que toca à dimensão ontológica, pode-se mencionar que ela está ligada a um conhecimento norteador, sendo que este deve permitir, aos sujeitos, a produção de saberes para uma melhor compreensão dos elementos que condicionam uma certa práxis social (KOERICH et al, 2009). Os fins desta pesquisa são desejados pela própria coletividade, o que demanda, do pesquisador, a necessidade de produzir conhecimentos que possam permitir a reestruturação de certos processos formativos (FRANCO, 2005). Em relação à dimensão de caráter epistemológico, menciona-se que, para o seu exercício, o pesquisador mergulhe na intersubjetividade da dialética do coletivo.

Para tanto, o pesquisador deve assumir uma postura diferenciada ao tratar e interpretar o conhecimento, visto que, ao mesmo tempo, busca conhecer e intervir na realidade daquele grupo que está sendo investigado (ENGEL, 2000). A união entre a pesquisa e ação, portanto, faz com que o pesquisador, essencialmente, tenha que adentrar no universo pesquisado, porém, tal necessidade, de forma alguma, anula a possibilidade de adotar uma postura neutra ao tratar os dados, pois este é um pressuposto da própria ciência (KOERICH et al, 2009). A neutralidade é uma forma de controlar as circunstâncias que perpassam por uma pesquisa, o que implica chamar a atenção para os pressupostos epistemológicos fundamentais, como a RC: 101855

Link de acesso: https://www.nucleodoconhecimento.com.br/educacao/a-ciencia$\underline{\text { metodologica }}$ 
priorização da dialética da realidade social e a historicidade dos fenômenos, da práxis, das contradições, das relações com a totalidade e análise da ação dos sujeitos com base em algumas circunstâncias (KOERICH et al, 2009).

A práxis, nesse contexto, deve ser concebida como uma forma básica de construir o conhecimento, pois, por meio dela, articula-se teoria e prática (FRANCO, 2005). No que tange ao conhecimento a ser analisado, este não se restringe à mera descrição, pois cabe ao pesquisador explicar tais transformações a partir daquilo que observa, isto é, por meio de um movimento que integra a dialética do pensamento e da ação (TRIPP, 2005). Como resultado, o conhecimento derivado dessa relação é capaz de transformar os sujeitos e as circunstâncias relacionadas ao meio do qual faz parte. A dimensão metodológica, por sua vez, demanda certos procedimentos que articulam a ontologia com a epistemologia da pesquisa-ação, o que implica instaurar no grupo observado uma dinâmica que integre os princípios e práticas dialógicas, participativas e transformadoras (TRIPP, 2005). Nessa dimensão, alguns elementos devem ser levados em consideração.

Dentre eles, pode-se mencionar a práxis. Ela é o ponto de partida e de chegada no que toca à construção e/ou ressignificação do conhecimento (FRANCO, 2005). Partese da noção de que o conhecimento apenas pode ser construído por meio das múltiplas articulações com a intersubjetividade. Diante de tal característica, a pesquisa-ação, para que seja bem articulada, deve ser realizada no ambiente natural da realidade a ser pesquisa, a fim de que os resultados coletados sejam verídicos, seguros e de qualidade (ENGEL, 2000). Há, nesse processo, uma certa flexibilidade, uma vez que o objetivo é o de captar uma realidade em processo de mudança. Desse modo, a metodologia deve ser capaz de permitir, ao pesquisador, a realização de certos ajustes, sendo que este deve caminhar de acordo com as sínteses provisórias. Tais sínteses são estabelecidas no próprio grupo (GRITTEM; MEIER; ZAGONEL, 2008). São esses elementos que apontam de que forma um certo contexto tem sido afetado. 
O método deve envolver o exercício contínuo de espirais cíclicas. Essas espirais levam em consideração algumas etapas fundamentais, como o planejamento, a ação, a reflexão, o ato da pesquisa, a ressignificação e o replanejamento, este último quando necessário (KOERICH et al, 2009). Sobre a pesquisa-ação, destaca-se, também, que, enquanto um processo investigativo, de educação e ação acontecem de maneira concomitante. Nesse sentido, as razões epistemológicas e metodológicas que perpassam pela atividade investigativa fazem com que o conhecimento seja produzido de maneira ativa, pois todos os envolvidos no processo devem colaborar (ENGEL, 2000). A investigação, nesse contexto, faz com que seja possível compreender as mudanças na realidade por meio da ação (TRIPP, 2005). O processo exige do pesquisador uma postura específica.

Ele se depara, frequentemente, com certos tipos de questionamentos, bem como com algumas demandas específicas, como a inserção na cultura que está analisando de novos sentidos, significados, representações, resistências, expectativas e vivências (FRANCO, 2005). O desafio com o qual o pesquisador se depara, por sua vez, é com tornar um ambiente novo, em processo de construção familiar. Em outras palavras, a mudança deve ser percebida por todos os envolvidos (KOERICH et al, 2009). pesquisador é um dos participantes do universo que está sendo investigado, contudo, a neutralidade da pesquisa é um princípio que deve ser considerado. Assim sendo, as suas percepções quanto ao fenômeno analisado não podem ser ignoradas, porém, o seu manuseio deve ser feito da maneira adequada. Um dos objetivos que pode ser alcançado por meio dessa estratégia diz respeito ao alcance, junto aos participantes, de uma maior confiança (KOERICH et al, 2009).

O ciclo da pesquisa-ação é iniciado com a fase exploratória. Nela, o diagnóstico sobre a realidade é feito e elabora-se um levantamento sobre o contexto, os problemas iniciais e sobre as eventuais ações (TRIPP, 2005). A partir disso, os pesquisadores e participantes estabelecem os principais objetivos da pesquisa. Esses devem estar interligados ao campo observado, aos atores e aos tipos de ações nos quais pretendese focar na atividade investigativa (FRANCO, 2005). Define-se, na sequência, o tema da pesquisa. Este é delimitado a partir de um problema prático relacionado a uma área RC: 101855

Link de acesso: https://www.nucleodoconhecimento.com.br/educacao/a-ciencia$\underline{\text { metodologica }}$ 
de pesquisa. Este é escolhido tendo como base os compromissos firmados entre a equipe de pesquisadores e os sujeitos que correspondem à situação em pauta (FRANCO, 2005). Contudo, o tema pode ser solicitado, ainda, pelos atores da situação. Deve ser de interesse tanto dos pesquisadores quanto dos sujeitos investigados para que todos assumam um papel ativo e contribuam com o desenvolvimento da pesquisa.

Escolhe-se, também, um marco teórico específico com o qual trabalhar, pois norteará toda a pesquisa. Em terceiro lugar, elege-se os problemas, isto é, o problema de pesquisa. É a partir da problemática que o tema ganha robustez (ENGEL, 2000). problema deve abarcar alguns pressupostos de pesquisa, como a análise e a delimitação da situação inicial; o desenho da situação final, a partir de critérios de desabilidade e factibilidade; a identificação de todos os problemas a serem resolvidos; a transposição desses problemas em ações correspondentes; e, por fim, a execução e a avaliação das ações (TRIPP, 2005). Nesse sentido, torna-se necessária a adaptação de um quadro de referências teóricas à realidade prática da pesquisa. $\mathrm{O}$ objetivo é o de que as informações sejam analisadas e interpretadas a partir de uma base teórica, porém, esta deve ser articulada com as experiências reais, coletadas, portanto, junto aos colaboradores do estudo (TRIPP, 2005).

Chega-se, então, às hipóteses. Apesar da falsa ideia que não há hipóteses, é necessário pensar de maneira cuidadosa acerca desta proposição, o que implica compreender as hipóteses como suposições formuladas pelo pesquisador que podem ou não serem confirmadas (KOERICH et al, 2009). As hipóteses admitem possíveis soluções para um problema de pesquisa e, assim, têm como objetivo a condução de uma linha de pensamento (KOERICH et al, 2009). O seminário também é uma das fases da pesquisa-ação, pois este desempenha um papel significativo no processo de tomada de decisões em uma investigação, bem como propicia a coordenação de atividades. $O$ objetivo de um seminário é a definição do tema e o estabelecimento de problemas com os quais a pesquisa irá operar. A elaboração da problemática para que os problemas sejam tratados, assim como as hipóteses de pesquisa, é um dos 
objetivos. Nascem os grupos de estudo e equipes de pesquisa que coordenam essas atividades.

As informações são provenientes de diferentes fontes e grupos, o que propicia o acesso às interpretações que fomentem os processos de estabelecimento de diretrizes de ação, bem como torna-se possível avaliar as ações e divulgar os resultados a partir de canais apropriados (KOERICH et al, 2009). A pesquisa-ação é operacionalizada, também, a partir dos campos de observação, amostragem e representatividade qualitativa. Esta pode abranger uma comunidade concentrada e/ou espalhada, contudo, a amostragem e a representatividade é um fator que pode ser discutido. Alguns estudos excluem a amostra, outros, recomendam o seu uso, outros, valorizam os critérios de representatividade qualitativa (FRANCO, 2005). Adentra-se na etapa da coleta de dados. As principais técnicas utilizadas são as entrevistas coletivas e/ou individuais, os questionários convencionais, o estudo de arquivos etc. Após a coleta das informações a partir dos grupos de observação, são discutidas, analisadas e interpretadas em conjunto.

\section{CONSIDERAÇÕES FINAIS}

O processo da atividade investigativa, da análise da realidade, bem como da avaliação das ferramentas e métodos qualitativos requerem uma certa dialogicidade, isto é, implica a busca pelo conhecimento reflexivo e firmação de um compromisso com a realidade concreta. Em outras palavras, requer um reconhecimento efetivo do suje ito e da realidade em análise a partir de um movimento dinâmico entre as partes envolvidas na investigação. Residem nessa possibilidade circular e dinâmica a ressonância e sustentação para a conquista de um novo espaço e/ou a conquista de um novo conhecimento. Assim, a pesquisa-ação enquanto uma ferramenta metodológica analisa ação humana a partir de um movimento comunicativo e participativo, o que favorece o compartilhamento de saberes e a elaboração de uma estrutura relacional de confiança e comprometimento com os sujeitos que integram a realidade a ser transformada. O seu objeto é a resolução ou esclarecimento dos problemas envoltos no grupo.

RC: 101855

Link de acesso: https://www.nucleodoconhecimento.com.br/educacao/a-cienciametodologica 
Durante o processo, necessita-se de um contínuo acompanhamento das decisões, das ações e de todas as atividades intencionais desenvolvidas pelos atores envolvidos na situação. Assim sendo, sob esse enfoque, a pesquisa não se limita a uma forma de ação, apenas, pois visa o aumento do conhecimento dos pesquisadores, bem como de seu nível de consciência, acerca das pessoas e/ou grupos envolvidos. A pesquisa promove muito mais do que um levantamento de dados e/ou proposições de intervenções práticas. Além das considerações aqui expostas, ressalta-se que a pesquisa-ação, dentre outras questões, agrega discussões e explicações reais, atuais e coerentes que possibilitam a geração de um conhecimento descritivo, porém, crítico, acerca das situações vivenciadas nos mais diversos ambientes sociais. Promove, portanto, novas formas de expressão e reflexão a respeito dos significados e sentimentos dos participantes atribuídos na análise da situação-problema em questão.

\section{REFERÊNCIAS}

ANDRÉ, M. E. D. A. Etnografia da prática escolar. Série Prática Pedagógica. Campinas: Papirus; 2000.

BARBIER, R. A pesquisa-ação. Tradução Lucie Didio. Brasília: Plano, 2002.

CARR, W.; KEMMIS, S. Teoria crítica de la enseñanza. Barcelona: Martinez Roca, 1988.

ENGEL, G. I. Pesquisa-ação. Educar em Revista, n. 16, p. 181-191, 2000.

FRANCO, M. A. S. Pedagogia da pesquisa-ação. Educação e pesquisa, v. 31, n. 3, p. 483-502, 2005.

GRITTEM, L.; MEIER, M. J.; ZAGONEL, I. P. S. Pesquisa-ação: uma alternativa metodológica para pesquisa em enfermagem. Texto \& Contexto-Enfermagem, v. 17, n. 4, p. 765-770, 2008.

$\mathrm{KOERICH}, \mathrm{M}$. S. et al. Pesquisa-ação: ferramenta metodológica para a pesquisa qualitativa. Revista Eletrônica de Enfermagem, v. 11, n. 3, p. 717-723, 2009.

RC: 101855

Link de acesso: https://www.nucleodoconhecimento.com.br/educacao/a-cienciametodologica 
LEWIN, K. Problemas de dinâmica de grupo. São Paulo: Cultrix, 1946.

MIRANDA, M. G. de.; RESENDE, A. C. A. Sobre a pesquisa-ação na educação e as armadilhas do praticismo. Revista Brasileira de Educação, v. 11, n. 33, p. 511-518, 2006.

MORIN, A. Pesquisa-ação integral e sistêmica: uma antropopedagogia renovada. Tradução Michel Thiollent. Rio de Janeiro: DP\&A, 2004.

PEREIRA, E. M. A. Professor como pesquisador: o enfoque da pesquisa-ação na prática docente. In: GERALDI, C. M. G.; FIORENTINI, D.; PEREIRA, E. M. A. (Org). Cartografias do trabalho docente: professor(a) - pesquisador(a). Coleção Leituras no Brasil. Campinas: Mercado das Letras, 2001. p. 153-81.

ROLIM, K. M. C. et al. Mulheres em uma aula de hidroginástica: experenciando o interrelacionamento grupal. Revista Brasileira em Promoção da Saúde, v. 17, n. 1, p. 8-13, 2004.

THIOLLENT, M. Notas para o debate sobre pesquisa-ação. In: BRANDÃ O, C. (Org.). Repensando a pesquisa participante. São Paulo: Brasiliense, 1984. p. 82-103.

TRIPP, D. Pesquisa-ação: uma introdução metodológica. Educação e pesquisa, v. 31, n. 3, p. 443-466, 2005.

Enviado: Novembro, 2021.

Aprovado: Novembro, 2021. 